\title{
Trauma and Emergency Care
}

\section{A complicated course of extensor carpi ulnaris tendon luxation}

\author{
Ingo Schmidt ${ }^{1,2 *}$ and Tino Beylich ${ }^{2}$ \\ ${ }^{1}$ Medical Centre Wutha-Farnroda (Department of Orthopaedics and Hand Surgery), Ringstr. 20, 99848 Wutha-Farnroda, Germany \\ ${ }^{2}$ Hospital Bad Salzungen GmbH (Department of Traumatology and Orthopaedics, Teaching Hospital of the Friedrich-Schiller-University Jena, Germany), \\ Lindigallee 3, 36433 Bad Salzungen, Germany
}

\begin{abstract}
Background: Psychological disorders may have influence on functional outcome after wrist and hand surgery, and this condition should not be underestimated. Aims: The aim of this article is to describe one exemplary case in which an interim poor functional outcome was not based on surgical failure.

Methods: A 40-year-old woman presented with left non-traumatic extensor carpi ulnaris tendon luxation primarily treated by surgical repair of the fibro-osseous tunnel utilizing the extensor retinaculum. The early functional outcome regarding supination of her forearm was poor that required revision surgery, however, a surgical failure could be excluded. Therefore, a psychological disorder had to be suggested.

Results and conclusion: In order to manage this critical situation, a meeting was held involving the surgeon, the patient, and the physical and occupational therapists. The specific Feldenkrais method for rehabilitation was applied that resulted at the end in an excellent functional outcome. However, before suggesting a psychological disorder as possible cause for poor functional outcome, a surgical failure should be excluded in every instance with revision surgery (i.e. „second look“).
\end{abstract}

Abbreviations: ECU: Extensor carpi ulnaris; CRPS: Chronic
regional pain syndrome

\section{Introduction}

The extensor carpi ulnaris tendon originates from the lateral epicondyle of the humerus and the dorsal surface of the ulna, passes through the groove dorsally at the ulnar head within a fibro-osseous tunnel of extensor retinaculum (6th compartment) (Figure 1A), having an own tendon subsheath for its stabilization there, and inserts on the base of the 5th metacarpal medially angled to its position in the groove of ulnar head.

ECU tendon luxation out off its groove is uncommon and can be caused either by an injury or by chronic tendinopathy / tenosynovitis subsequently leading to insufficiency or disruption of its tendon subsheath accompanied by elongation of the extensor retinaculum. Surgical treatment is detected when conservative treatment (splinting) has been failed, however, all surgical procedures are not free of any complications. We present one complicated course after surgical treatment that was not based on surgical failure but on a specific condition of chronic regional pain syndrome (CRPS) type I.

\section{Case presentation}

A 40-year-old skinny woman (height: $1,75 \mathrm{~m}$, body weight: 64 $\mathrm{kg}$ ) reported painful snapping at her left ulnar head when turning the forearm for many years. A real injury was not remembered in the past, but generally she has hypermobile joints. At clinical examination, a luxation of the ECU tendon ulnar- and palmarwards out over the ulnar rim of its groove could be provoked when turning her forearm from pronation to supination (Figure 1B, Preoperative video of the patient supplementary material). Surgical revision was detected by us.
Dorsal surgical incision was done typically at the left ulnar head and distal ulna. After incision of the marked elongated extensor retinaculum (6th dorsal compartment) we could no longer see a sufficient ECU tendon subsheath, and the luxation of the ECU tendon in ulnar and palmar direction could be confirmed when turning the forearm from pronation to supination (Figure 2A). The 6th compartment was reconstructed with gathering of the extensor retinaculum which was fixated both at the ulnar and radial rim of the groove utilizing two titanium microanchors. After that, the ECU tendon was sufficiently stabilized again in its groove (Figure 2B). Primary wound closure was done, and the overall left arm was immobilized in a plaster splint (suggesting for five weeks). Wound healing was uneventful.

Three weeks after surgery, supination of the left forearm was completely painful restricted. Hence, the plaster splint was completely removed and physical therapy was started. However, three months after surgery there was unchanged a marked painful restriction of supination, and the patient tried to compensate her loss of supination by adduction and external rotation of the arm in her shoulder joint (Figure 2C). Hence, revision surgery was detected by us. Noted that

${ }^{\star}$ Correspondence to: Ingo Schmidt, Medical Centre Wutha-Farnroda (Department of Orthopaedics and Hand Surgery), Ringstr. 20, 99848 WuthaFarnroda; Hospital Bad Salzungen GmbH (Department of Traumatology and Orthopaedics, Teaching Hospital of the Friedrich-Schiller-University Jena, Germany), Lindigallee 3, 36433 Bad Salzungen, Germany, E-mail: schmidtingo62@googlemail.com

Key words: extensor carpi ulnaris, luxation, surgical repair, functional outcome, psychological disorder, rehabilitation, feldenkrais method

Received: March 29, 2020; Accepted: April 03, 2020; Published: April 08, 2020 


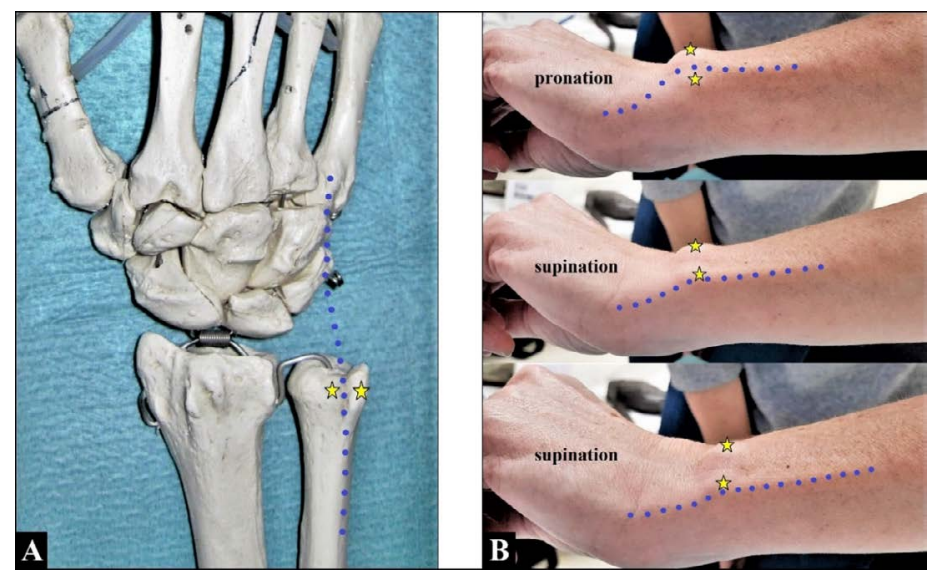

Figure 1. (A) The anatomical relationship of the ECU tendon (blue pointed line) to the groove dorsally at the ulnar head (yellow stars). (B) The ECU tendon (blue pointed line) luxates ulnar- and palmarwards out over the ulnar rim of its groove (yellow stars) when turning the patient's forearm from pronation to supination (provide also the patient's video in supplementary material). Note that the ECU tendon course is medially angled to its insertion on the base of the 5th metacarpal when the forearm is held in pronation (i.e. relaxed course), whereas in supination the ECU tendon is maximally tensioned as predisposing factor for its luxation

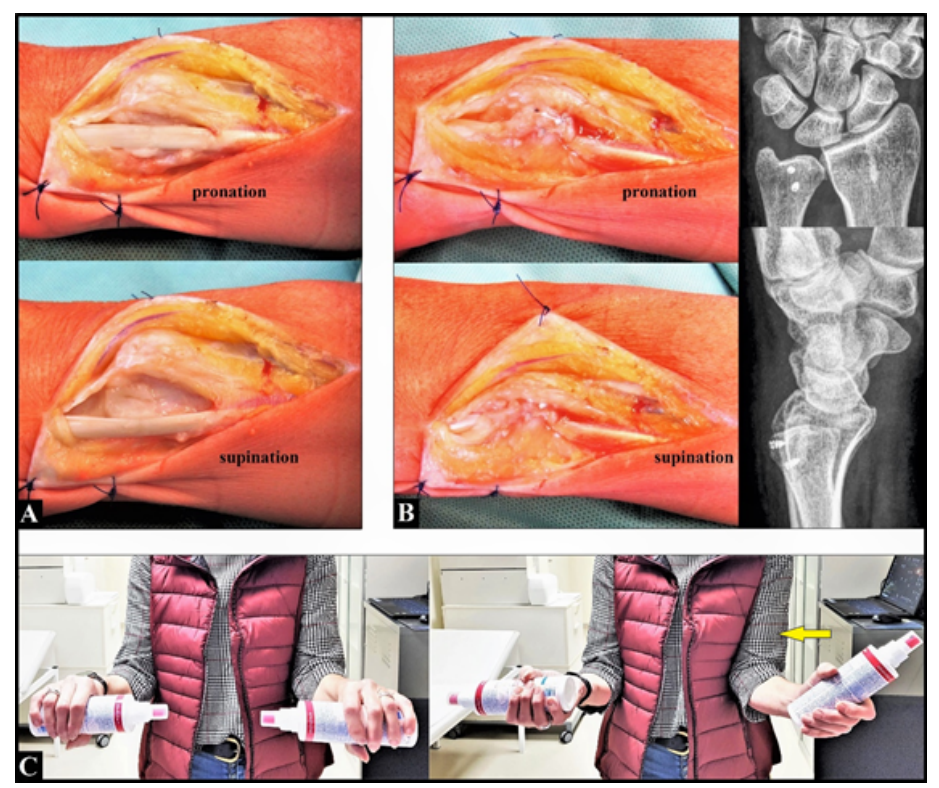

Figure 2. (A) Intraoperatively, the ECU tendon luxation out over the ulnar rim of its groove could be confirmed when turning the forearm from pronation to supination. (B) Intra- and postoperatively, the ECU tendon could be sufficiently stabilized in its groove utilizing the extensor retinaculum. Note the correctly intraosseous placed two microanchors at the ulnar head. (C) Three months postoperatively, there was a marked restriction of supination, and the patient tried to compensate the loss of function with adduction and external rotation in her shoulder joint (yellow arrow)

there was no local swelling and hyperthermia, and the patient reported "anxiety that she might lose her day time job“.

Revision surgery was performed in subaxillar plexus anaesthesia. Before surgical incision a closed mobilization was done, after that, a nearly complete restoration of forearm supination could be achieved (Figure 3A). Surgical incision was performed via the pre-existing approach. We saw a sufficient formerly reconstructed 6th compartment in the absence of any (sub)luxation tendencies of the ECU tendon, and the ECU tendon showed an excellent gliding through its fibro-osseous tunnel with a complete restoration of pronation and supination (Figure $3 \mathrm{~B}-\mathrm{C}$ ).

However, three weeks after revision surgery, supination was completely restricted again associated with pronounced muscle tightness at the forearm (Figure 4A), and the patient subjectively reported: „my left arm is no longer a piece of me“. Therefore, a meeting was held involving the surgeon, the patient, and the physical and occupational therapists indicating the specific Feldenkrais method. Six months after initial surgery (i.e. three months after revision surgery) the patient was very satisfied with her outcome associated with complete restoration of pronation and supination (Figure 4B). The patient could be completely re-employed in her original occupation as a manual worker in manufacturing orthotic devices.

\section{Discussion}

ECU tendon luxation, mainly observed out over the ulnar rim of its groove in ulnar and palmar direction, is a rare condition and can often be overlooked or misdiagnosed. The rationale behind this condition is that ECU tendon angles medially at the wrist before inserting on the base of the 5th metacarpal. The angle formed becomes more acute with the forearm in supination and the wrist in ulnar deviation. In this position, the ECU tendon is maximally tensioned and is inclined to (sub)luxate if the subsheath that contains it is incompetent, whereas in 


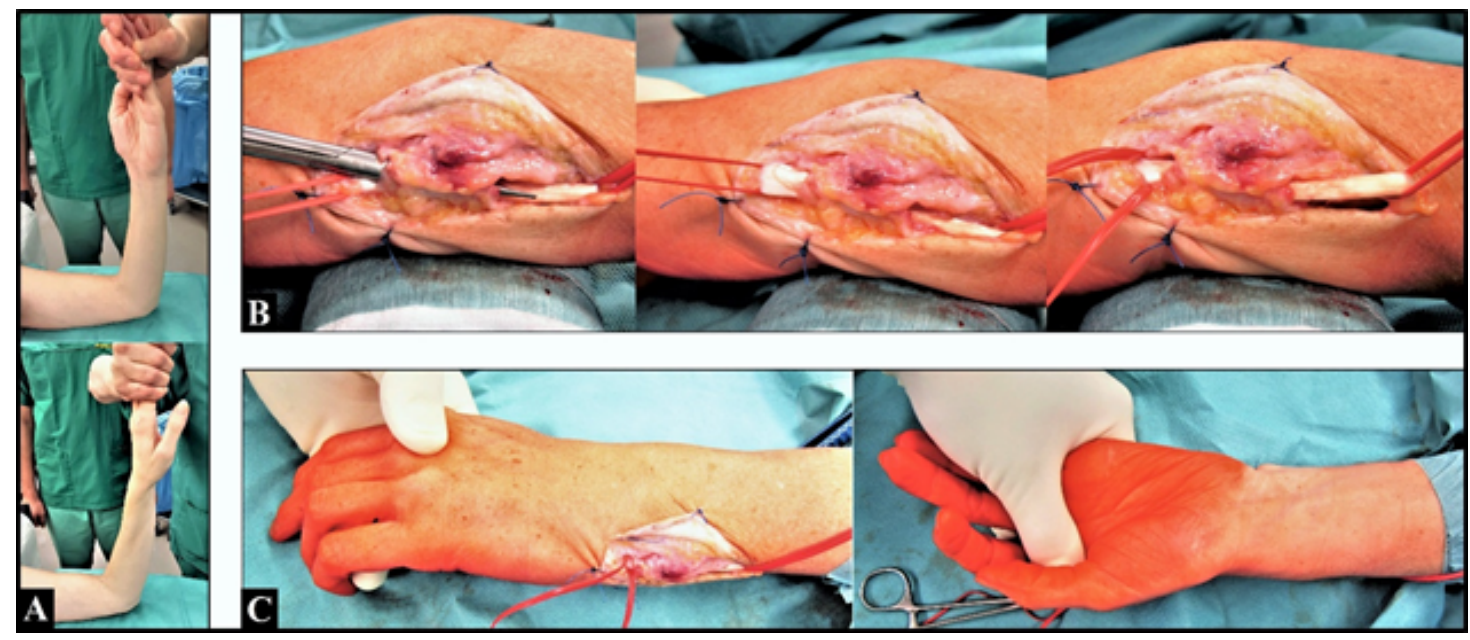

Figure 3. (A) Under the condition of subaxillar plexus anaesthesia before revision surgery: note the complete pronation and nearly complete supination. (B) Revision surgery: the formerly reconstructed fibro-osseous tunnel was not too tight, and the ECU tendon showed an excellent gliding. (C) At the end of revision surgery: complete pronation and supination without any passive obstacles in mobility

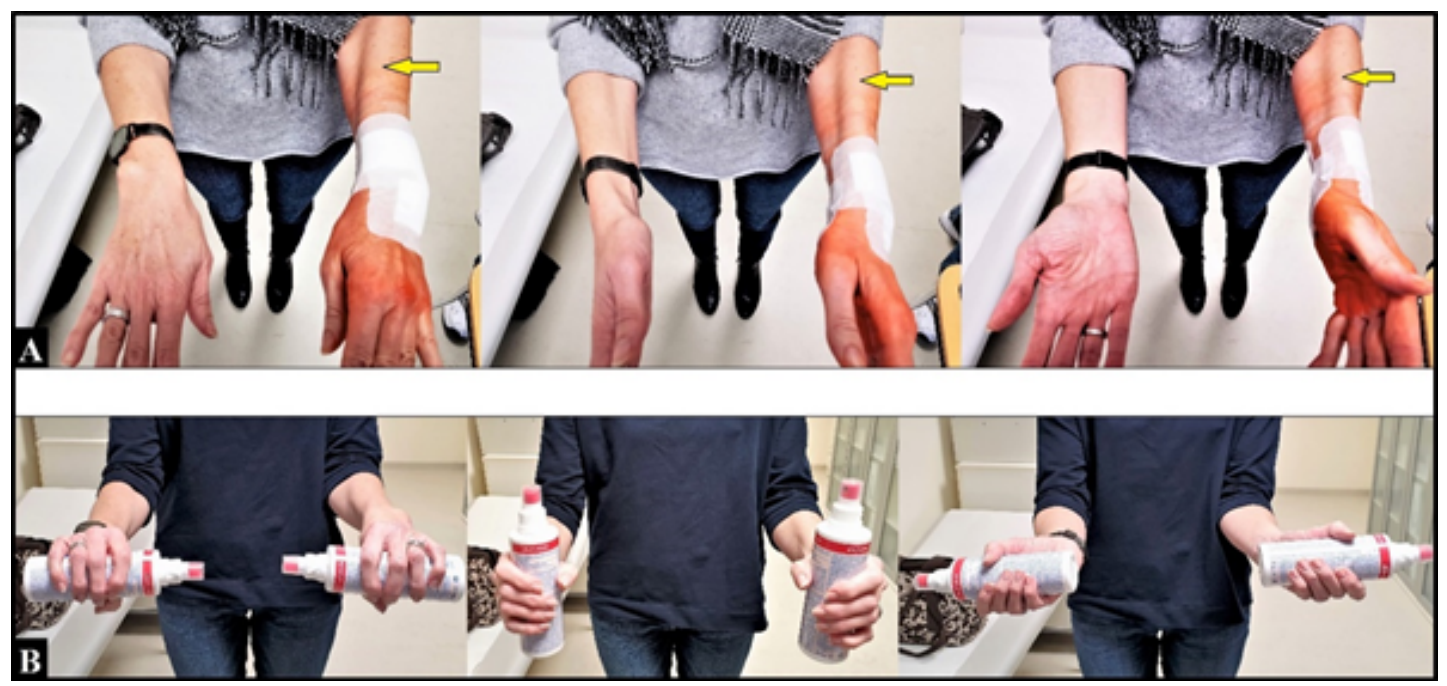

Figure 4. (A) Three weeks after revision surgery: supination was completely restricted again. Note the marked tightness of the brachioradialis muscle (yellow arrows) as compared to the uninjured right forearm. (B) Three months after applying the Feldenkrais method: complete restoration of forearm's supination

pronation the ECU tendon adopts a relaxed course to its insertion and causes minimal force on the subsheath (Figure 1B) [1-5]. Therefore, clinical examination should be done in every instance under dynamic conditions (Figure 1B, Preoperative video of the patient - supplementary material). ECU tendon luxation can be diagnosed as well utilizing the so-called „ice cream scoop test“ in which the patient moves the wrist from pronation-ulnar deviation to flexion-ulnar deviation and finally to flexion-supination against resistance and direct palpation of the tendon by the examiner [6]. ECU tendon (sub)luxation are classified into three subtypes: (A) the fibro-osseous sheath is disrupted at its ulnar side and the tendon may lie beneath the fibro-osseous sheath, (B) the sheath is disrupted from its radial wall and the tendon may overlie it and prevent healing, and $(\mathrm{C})$ the tendon dislocates into a false pouch formed by stripping of the periosteum from the ulna $[7,8]$.

Traumatic ECU tendon luxation, either by direct trauma or by acute / repetitive rotational wrist injuries, is mainly observed in professional athletes such as in water-polo players, tennis players, and golfers at the dominant side [2,8-11]. Predisposing factors for non-traumatic ECU (sub)luxation could be congenital flattening of the groove at the ulnar head and/or congenital or required impaired mechanical properties of the tendon subsheath due to chronic overload for example in pre-existing hypermobile joints (i.e. hyperlaxity) which is similar in peroneal tendon luxation (Figures 5 A-B) $[2,12]$. Surgical reconstruction includes various options: a direct repair is possible in acute lesions when the tendon subsheath is disrupted at the radial rim whereas the use of the extensor retinaculum (slings, strips, pedicled or free flaps) is recommended in cases of an ulnar disruption [7,9,13-15], and deepening of the groove which is similar as well for surgical treatment of peroneal tendon (sub)luxation (Figures 6 A-D) $[2,12,14,16,17]$. However, deepening of the groove at the ulnar head remains controversial, it can be followed by recurrent subluxation or rim fractures $[18,19]$. Another approach for surgical treatment of chronic tendinopathy with or without subluxation is lengthening of the ECU tendon in order to reduce the forces on the subsheath while supination [1]. Postoperative care should include generally physical and/or occupational therapy in order to achieve satisfactory functional outcomes [20,21]. 


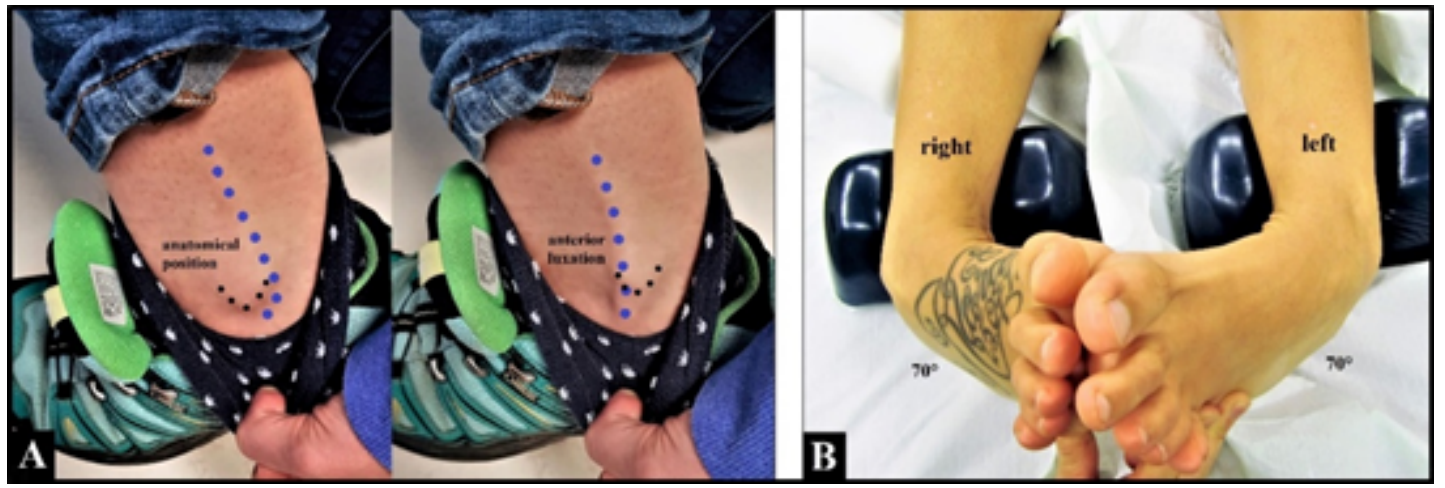

Figure 5 (Example for left peroneal tendon luxation, 36-year-old female, indirect rotational injury of the lower leg against the ankle while abruptly snowboard stopping maneuver, physical therapist by profession). (A) The anterior peroneal tendon luxation (blue pointed lines) out over the ventral rim of its groove at the lateral malleolus (black points) could be provoked by the patient when abruptly stopping her fast gait. (B) Hyperlaxity in both ankle joints of this patient must be considered as predisposing factor for peroneal tendon luxation

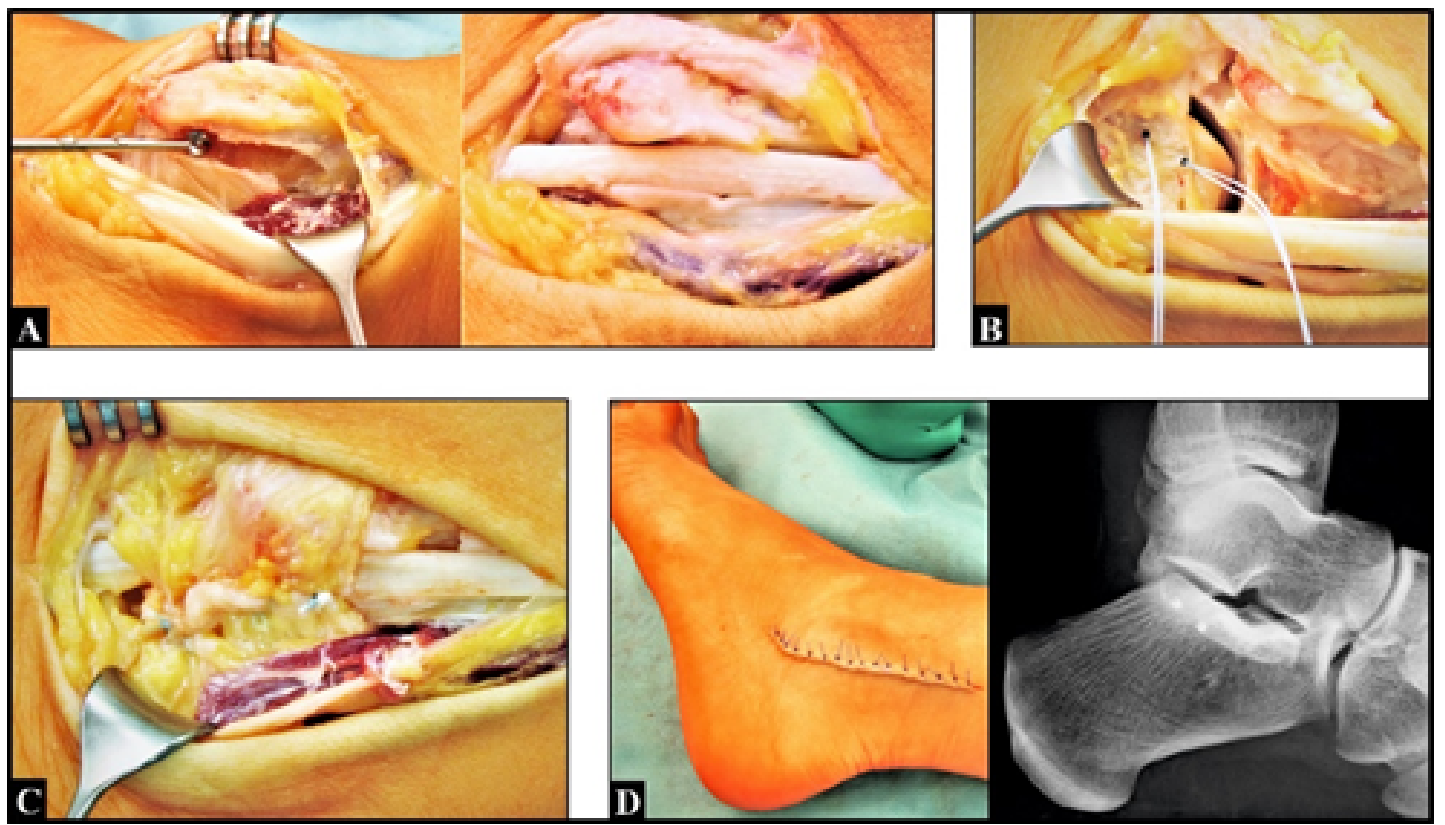

Figure 6 (Same patient as in Figures 5 A-B). (A) Deepening the peroneal tendon groove at the lateral malleolus with a round burr. (B) Placement of two microanchors into the calcaneus for reconstruction of the peroneal tendon retinaculum. (C) Sufficiently reconstructed fibro-osseous tunnel for the peroneal tendon. (C) The further course was uneventful, note the correctly intraosseous placed two microanchors at the calcaneus adjacent to the lower ankle joint.

However, surgical reconstruction of the fibro-osseous tunnel utilizing the extensor retinaculum is not free of any problems. Longterm outcomes revealed that approximately one third of patients developed complications such as injuries of the sensory branches of the dorsal ulnar nerve, and stiffness or stenosing ECU tendinitis when the repair of the fibro-osseus tunnel was too tight [13]. With our patient, the latter could be ruled out as part of our revision surgery. Therefore, the pronounced muscle tightness resulting in complete restriction of forearm's supination had to be suggested as a specific condition of CRPS type I.

Poor outcome or development of CRPS type I based on psychological factors (anxiety, depression, or catastrophic thinking) with female predominance after wrist and hand surgery in the absence of surgical failures is a concern and unpredictable [22-32]. With our patient, psychological factors were probably the main causes of the interim poor functional outcome (,anxiety that she might lose her day time job“, „my left arm is no longer a piece of me“). Therefore, the initiated meeting involving the surgeon, the patient, and the physical and occupational therapists was absolutely mandatory to manage this critical situation.

The Feldenkrais method, detected by us, is named after its founder the Israeli physicist, engineer, and self defense technique teacher (judo, jiu jitsu, krav maga) with interest in alternative medicine and neuropsychology Dr. Moshe Feldenkrais (1904-1984), and is described as a method of motion-related somatic learning („learning how to learn") [33,34]. This method is widely applied in medical, athletic, pedagogic, and artistic fields [35]. It is based on the fact that we interact with the brain through movement and stimulate it to form new patterns. We use movement in the Feldenkrais method, but unlike many other methods, we do not use it with the intention of stretching or training muscles, but to bring about changes in the brain. There is a natural urge for the brain to develop and to interact with the environment more precisely, effectively and appropriately. This natural process is increasingly known today under the term neuroplasticity: the ability 
of the brain to make new connections at any time - its real task for a lifetime. Some case reports revealed clinical improvements in muscle stiffness, recovery of hand function, and playing instruments [36].

\section{Conclusion}

We present one complicated course after surgical repair of an ECU tendon luxation that was not based on a surgical failure. For those conditions, psychological disorders should be born in mind which can be managed with an interdisciplinary approach.

\section{Funding}

None.

\section{Conflicts of interest}

The authors declare no conflict of interest, financial or otherwise.

\section{Acknowledgements}

The authors would like to thank the physical and occupational therapists for their excellent support in treatment of our patient.

\section{Supplementary material}

Supplementary material (preoperative video of the patient) is available on the publishers website along with the published article.

\section{References}

1. Fisch R, Meals C, Meals R (2020) Effectiveness of extensor carpi ulnaris tendon lengthening in treating four patients with tendinopathy. J Hand Surg Eur Vol 45: 88-90.

2. MacLennan AJ, Nemechek NM, Waitayawinyu T, Trumble TE (2008) Diagnosis and anatomic reconstruction of extensor carpi ulnaris subluxation. J Hand Surg Am 33: 59-64. [Crossref]

3. Ruchelsman DE, Vitale MA (2016) Extensor Carpi Ulnaris Subsheath Reconstruction. J Hand Surg Am 41: e433-e439. [Crossref]

4. Taleisnik J, Gelberman RH, Miller BW, Szabo RM (1984) The extensor retinaculum of the wrist. J Hand Surg Am 9: 495-501. [Crossref]

5. Spinner M, Kaplan EB (1970) Extensor carpi ulnaris. Its relationship to the stability of the distal radio-ulnar joint. Clin Orthop Relat Res 68: 124-129.

6. Ng CY, Hayton MJ (2013) Ice cream scoop test: a novel clinical test to diagnose extensor carpi ulnaris instability. J Hand Surg Eur Vol 38: 569-570.

7. Inoue G, Tamura Y (1998) Recurrent dislocation of the extensor carpi ulnaris tendon. Br J Sports Med 32: 172-174.

8. Inoue G, Tamura Y (2001) Surgical treatment for recurrent dislocation of the extensor carpi ulnaris tendon. J Hand Surg Am 26: 556-559.

9. Stathopoulos IP, Raptis K, Ballas EG, Spyridonos SP (2016) Recurrent dislocation of the extensor carpi ulnaris tendon in a water-polo athlete. Trauma Mon 21: e19551.

10. Pratt RK, Hoy GA, Bass Franzcr C (2004) Extensor Carpi Ulnaris Subluxation or Dislocation? Ultrasound Measurement of Tendon Excursion and Normal Values. Hand Surg 9: 137-143. [Crossref]

11. Montalvan B, Parier J, Brasseur JL, Le Viet D, Drape JL (2006) Extensor carpi ulnaris injuries in tennis players: a study of 28 cases. Br J Sports Med 40: 424-429.

12. Neubert M, Steinbrück K (1991) Dislocation of the peroneal tendon--clinical aspects and therapy. Sportverletz Sportschaden 5: 175-177.

13. Verhiel SHWL, Özkan S, Chen NC, Jupiter JB (2020) Long-Term Outcomes After Extensor Carpi Ulnaris Subsheath Reconstruction With Extensor Retinaculum. Tech Hand Up Extrem Surg 24: 2-6. [Crossref]

14. Allende C, Le Viet D (2005) Extensor carpi ulnaris problems at the wrist--classification, surgical treatment and results. J Hand Surg Br 30: 265-272.

15. Cift H, Ozkan K, Söylemez S, Ozkan FU, Cift HB (2012) Ulnar-sided pain due to extensor carpi ulnaris tendon subluxation: a case report. J Med Case Rep 6: 394 [Crossref]
16. Iorio ML, Huang JI (2014) Extensor carpi ulnaris subluxation. J Hand Surg Am 39: 1400-1402. [Crossref]

17. Davda K, Malhotra K, O'Donnell P, Singh D, Cullen N (2017) Peroneal tendon disorders. EFORT Open Rev 2: 281-292. [Crossref]

18. Graham TJ (2012) Pathologies of the extensor carpi ulnaris (ECU) tendon and its investments in the athlete. Hand Clin 28: 345-356. [Crossref]

19. Puri SK, Morse KW, Hearns KA, Carlson MG (2017) A Biomechanical Comparison of Extensor Carpi Ulnaris Subsheath Reconstruction Techniques. J Hand Surg Am 42: 837.e1-837.e7. [Crossref]

20. Hirsch, U, Zobel J (2018) [Occupational Therapy in Orthopedics and Accident Surgery]. Rehabilitation (Stuttg) 57: 201-217.

21. Shah RF, Zhang S, Li K, Baker L, Sox-Harris A, Kamal RN (2019) Physical and Occupational Therapy Use and Cost After Common Hand Procedures. $J$ Hand Surg Am pii: S0363-5023(19)31390-1395. [Crossref]

22. Teunis T, Bot AG, Thornton ER, Ring D (2015) Catastrophic Thinking Is Associated With Finger Stiffness After Distal Radius Fracture Surgery. J Orthop Trauma 29: e414-420.

23. Sandroni P, Benrud-Larson LM, McClelland RL, Low PA (2003) Complex regional pain syndrome type I: incidence and prevalence in Olmsted county, a population-based study. Pain 103: 199-207. [Crossref]

24. de Mos M, de Bruijn AG, Huygen FJ, Dieleman JP, Stricker BH, Sturkenboom MC (2007) The incidence of complex regional pain syndrome: a population-based study. Pain 129: 12-20. [Crossref]

25. Crijns TJ, van der Gronde BATD, Ring D, Leung N (2018) Complex regional pain syndrome after distal radius fracture is uncommon and is often associated with fibromyalgia. Clin Orthop Relat Res 476: 744-750. [Crossref]

26. Calfee R, Chu J, Sorensen A, Martens E, Elfar J (2015) What Is the Impac of Comorbidities on Self-rated Hand Function in Patients With Symptomatic Trapeziometacarpal Arthritis? Clin Orthop Relat Res 473: 3477-3483.

27. Hoogendam L, van der Oest MJW, Tsehaie J, Wouters RM, Vermeulen GM, et al (2019) Psychological factors are more strongly associated with pain than radiographic severity in non-invasively treated first carpometacarpal osteoarthritis. Disabil Rehabil Nov 8: 1-6.

28. Ottenhoff JSE, Teunis T, Janssen SJ, Mink van der Molen AB, Ring D (2020) Variation in Offer of Operative Treatment to Patients With Trapeziometacarpal Osteoarthritis. $J$ Hand Surg Am 45: 123-130.e1. [Crossref]

29. Cheng H, Novak CB, Veillette C, von Schroeder HP (2020) Influence of psychological factors on patient-reported upper extremity disability. J Hand Surg Eur Vol 45: 71-76.

30. Jerosch-Herold C, Houghton J, Blake J, Shaikh A, Wilson EC, Shepstone L (2017) Association of psychological distress, quality of life and costs with carpal tunnel syndrome severity: a cross-sectional analysis of the PALMS cohort. BMJ Open 7: e017732. [Crossref]

31. Khan F, Shehna A, Ramesh S, Sandhya KS, Paul R (2017) Subjective symptomes of carpal tunnel syndrome correlate more with psychological factors than electrophysiological severity. Ann Indian Acad Neurol 20: 69-72.

32. Weis T, Boeckstyns ME (2009) The clenched fist syndrome: a presentation of eight cases and an analysis of the medicolegal aspects in Denmark. J Hand Surg Eur Vol 34: 374-378. [Crossref]

33. Ohry A, Tsafrir J (2000) David Ben-Gurion, Moshe Feldenkrais and Raymond Arthur Dart. Isr Med Assoc J 2: 66-67. [Crossref]

34. Palmer CF (2017) Feldenkrais Movement Lessons Improve Older Adults' Awareness, Comfort, and Function. Gerontol Geriatr Med 3: 2333721417724014. [Crossref]

35. Brummer M, Walach H, Schmidt S (2018) Feldenkrais 'Functional Integration' Increases Body Contact Surface in the Supine Position: A Randomized-Controlled Experimental Study. Front Psychol 9: 2023. [Crossref]

36. Ives JC, Shelley GA (1998) The Feldenkrais Method ${ }^{\circledR}$ in rehabilitation: a review. Work 11: 75-90. [Crossref]

Copyright: (C2020 Schmidt I. This is an open-access article distributed under the terms of the Creative Commons Attribution License, which permits unrestricted use, distribution, and reproduction in any medium, provided the original author and source are credited. 